\title{
Appropriate Methodology: \\ An Example using a Traditional African Board Game to measure Farmers' Attitudes and Environmental Images ${ }^{1}$
}

\section{David Barker}

\section{Appropriate methodology}

The recent growth of interest in the utility of indigenous environmental knowledge in Africa (Richards, 1975; Barker, Oguntoyinbo and Richards, 1976; O'Keefe and Howes, infra) has brought more sharply into focus the cross-cultural limitations of many conventional geographical methods for collecting perceptual and behavioural data. Elicitation techniques perfected in industrial societies are not automatically suitable in developing countries and so careful pre-testing and evaluation of methods assumes a vital role in research design. Indeed, Barker (1978) advocates a more conscious effort to use 'appropriate methodologies' in this type of behavioural research. The data collection process is part of a social contract between a researcher and local people, and the onus is on the former to ensure his techniques are appropriate to the cultural context in which they are to be used, and are tailored to the abilities and requirements of the community in which he works. The danger is that an uncritical reliance on transferred social science methodologies, often embodying culturebound assumptions about people's behaviour, can produce research conclusions that may be partial and possibly misleading.

Verandah story telling and traditional music and poetry are examples of locally important modes of social interaction in Africa, and are reservoirs of community expertise which can be incorporated into research designs. The purpose of this short paper is to illustrate how a similar simple, yet locally significant and familiar cultural pastime can be adapted and refined as a research tool. Field trials with local farmers at Oluwatedo village, Oyo State, Nigeria, examined several

\footnotetext{
1 Many of the ideas expressed in this paper are the result of fieldwork undertaken in conjunction with Paul Richards, Joyce Tait, David Atteh with the assistance of Sammy Ogunjimi, Robert Olanipekun and Sunday, at the village of Oluwatedo, Oyo State, Nigeria, in preparation for the Workshop on Perception of Environmental Quality, organised by the International Geographical Union and held at the University of Ibadan, Nigeria, July 22-29 1978. The author gratefully acknowledges financial support for this fieldwork from the Hayter Travel Award Committee of the University of London.
}

different methods of measuring their perception of weeds, pests and farm methods. One of the most interesting and successful of these attempted to generate information and stimulate discussion using the format of a traditional Yoruba game Ayo.

\section{The diffusion of the ancient game of Mancala}

$A$ yo is the Yoruba version of a game ethnologists generically term Mancala, which originated in Egypt and is the oldest of all games still played in the world. The name Mancala is derived from an Arabic word naqala which means 'to move' and the movement of the game itself across the globe is interesting; it is the only major game to spread from west to east (unlike ludo, dominoes, dice, etc.). It diffused west and south during the spread of Islam and was also carried to the West Indies at the time of the African slave trade. Its present geographical distribution is thus very extensive and covers most of Africa, where it is claimed by some to be its national game, the Middle East and south east Asia. Murray (1952) describes over two hundred current versions of the game.

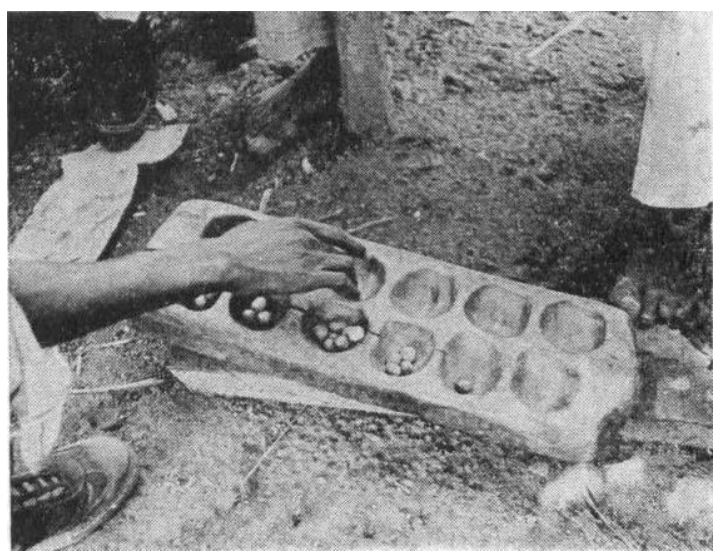

(Photo: P. Richards) Mancala board in use as a means of scaling farmers' investment priority preferences concerning weed and pest control.

$A y o$ is a Yoruba word meaning 'the game' and is played on a wooden board which has two rows of six holes carved into it, as in figure 1. Other 
African designs sometimes include additional storage holes, offset at the end of the board for captured pieces. Where the game differs more substantially there may be more than six holes per row, as in some East African versions of Bao, and perhaps even four or six rows. $A$ yo is played with 48 'pieces', normally canna lily seeds, although in general any locally available items such as seeds, shells, beans or stones are used. Although some versions of Mancala, like the Akan game Oware in Ghana, can be played with four or six players, $A$ yo is for two people and the object is to capture more seeds than your opponent. The game proceeds alternately, each player removing the contents of one of his own holes and placing seeds, one per hole, serially in an anticlockwise direction. Different versions of Mancala have different rules about how seeds may be captured.

The game is very skilful, played at high speed, and is widely available in African communities because the basic equipment is easy and cheap to produce from local materials; it can even be played by scooping holes in the ground and using stones. In addition to being a popular pastime (it was once the Royal Game of the Ashantis), it is also a device for teaching young children skills in mental arithmetic.

\section{The Atteh board}

The original idea and adaptation of $A y o$ as a research tool came from David Atteh and Paul Richards who devised a board whose basic design is shown in Figure 2. Atteh, and also Flynn and Knight, have applied techniques which utilise this board as part of carefully integrated surveys $^{2}$ of farming behaviour and indigenous knowledge in south west Nigeria. During the course of these interviews a farmer is asked to imagine he has N100 to invest in his farm and

\footnotetext{
2 This research is in progress at IITA, Ibadan, Nigeria. The Atteh board used at oluwatedo was kindly made available to the participants of the field trials by the IITA team.
}

Figure 1. The basic layout of an $A$ yo board
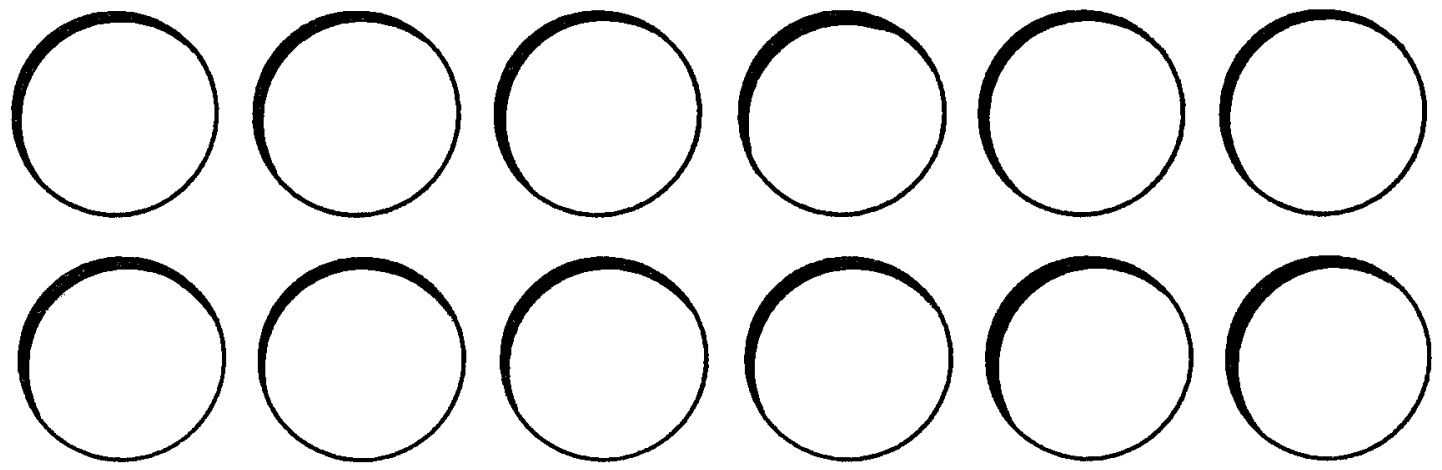

Figure 2. The basic layout of the Atteh board

small scale farmers

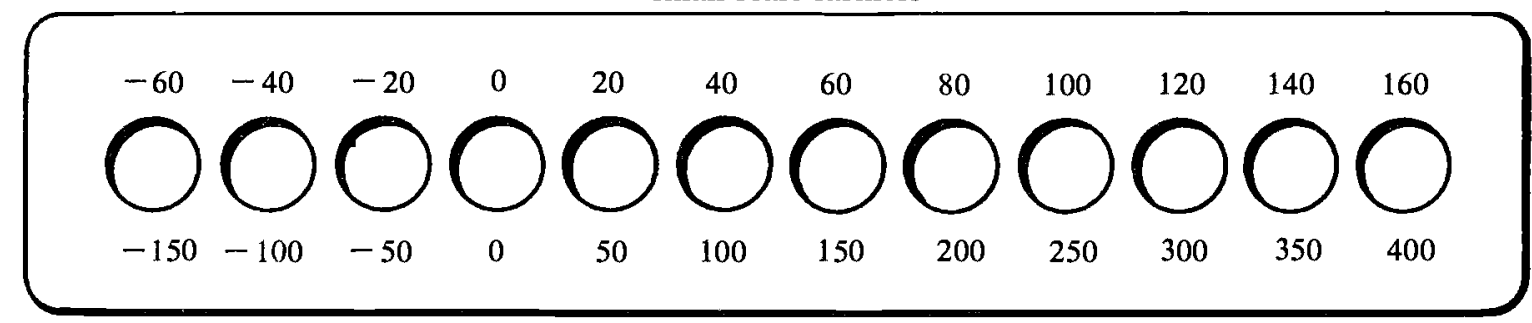

large scale farmers 
to indicate his likely returns over the next five years. $\mathrm{He}$ is given five $A$ yo seeds and drops them into the holes representing these returns. Next, he is given three seeds and asked to show his best, worst and expected returns over this five year period. Both procedures lead on to more general questions from the interview schedule and discussion about his decision making.

A variation tried during the Oluwatedo field trials using this board was to examine farmers' preferences for different combinations of farm returns over three year periods. One farmer, for example, preferred returns of N100, N150 and $\mathrm{N} 200$ to $\mathrm{N} 400, \mathrm{~N} 200$ and $-\mathrm{N} 100$, and explained his liking for the smaller net gain of the first three year combination in terms of his not wanting to make a loss for any given year. Similarly, he preferred N200 and N250 over two years to $\mathrm{N} 50$ and $\mathrm{N} 400,{ }^{3}$ arguing that the first was more 'progressive' because it yielded a steady income.

\section{Perception studies and the Ayo board}

If the $A$ yo board is viewed as a two dimensional matrix, with the holes being equivalent to the matrix cells within which frequencies (i.e. numbers of seeds) can be represented, there are innumerable methods and scenarios for eliciting information, and the information need not be restricted to farming behaviour. For example, a row can be defined as an attitude scale of six divisions where the two end holes are assigned values of +3 and -3 and intermediate holes are the discrete positions between. Using this idea, farmers at Oluwatedo were able to scale the severity of the grasshopper pest, Zonocerus variegatus, for each of a number of preceding years by simply dropping a seed (for each year) into the appropriately positioned hole, and then describing and explaining their decisions. As an extension to this technique, a second pest might be selected and its severity scaled in the same way along the second row of the board; comparisons between pests are then possible by commenting on their relative positions along the scales.

An alternative adaptation of the $A y o$ board is to elicit and scale personal constructs from a repertory grid. ${ }^{4}$ Suppose a farmer is asked to contrast a set of three weeds (the grid elements) and he provides a construct such as 'easy to cleardifficult to remove'. The two poles of the con-

\footnotetext{
3 The Nigerian currency unit is the Naira, roughly equivalent

4 For an introduction to the literature on Personal Construct Theory and repertory grids, see D. Bannister and F. Fransella, 1971 .
}

struct can be defined as each end hole of a particular row on the board. All the repertory grid elements, which might be a set of specimen weeds, can now be scaled along the construct. To do this, each weed is represented by an Ayo seed, and the farmer drops them into those holes whose positions reflect how easy or difficult each weed is to clear. Thus the construct can be scaled in a way which permits the farmer to view each scaling decision in the light of his previous decisions about the other weeds in the set.

The procedure can be taken a stage further and another construct defined and scaled alongside the first using the second row on the board. Constructs may then be compared directly and methods devised to determine their superordinacy relative to each other. Again, weeds can be compared by asking questions about their different positions on each construct.

Only slight modifications are necessary to construct $A$ yo boards with a variety of different properties in a similar way to the Atteh board. For example, a board could have enough holes to correspond to the months of the local calendar year. This might be a quick method for determining the proportion of time spent on different farm operations through the year. Also, semantic differential scalings could be obtained by using boards whose rows contain an odd number of holes, or boards might be embellished by painting them green and black to indicate the favourable and unfavourable parts of a scale. Another strategy is to give a handful of $A$ yo seeds to farmers to represent a given amount of money and ask them to allocate the seeds between holes to indicate their expenditure over the next year, where each hole represents a different variety of yam or rice.

\section{Some implications for research methodology}

It could be argued that any search for 'appropriate' research methods will result, implicitly, in a compromise between the field techniques of anthropology and those of 'western' social science. The constraints under which many social scientists work in the developing countries often preclude the use of the classic field techniques of the anthropologist (Crane and Angrosino, 1974), which normally take many years to bear their rich fruit. On the other hand, much of the impetus to engage in the experimental work described here arose from a felt need to eschew the central role of the questionnaire, traditionally important in the design of geographical research into agricultural systems. 
The view which regards participant observation and survey research as two extremes of a continuum of research techniques is, however, not particularly helpful. Thus whilst Warwick (1973) provides a useful focus for an informal costbenefit analysis of the two, his conclusions are disappointing in their self-evidence: the strength of sample surveys lies in their greater potential for quantification, replication and generalisation whilst participant observation scores on qualitative depth, flexibility and more detailed analyses of social processes. Indeed, there are much more useful frameworks than the social surveyparticipant observation continuum for evaluating research elicitation techniques (see for example, Whyte, 1977).

Cole, Gay, Glick and Sharp (1971), studying the mathematical ability of the Kpelle in Liberia, faced similar methodological problems in developing suitable elicitation techniques, and advocated an 'experimental anthropology' in which they adapted and integrated methods from psychology, anthropology and sociology. They stress the importance of setting people tasks within the home cultural milieu (i.e. in familiar settings) and involving routine activities to elicit categories of response relating to everyday experience. Thus they refute the view that posing hypothetical questions and tasks to people in non-literate societies violates cultural norms and generates atypical cognition. Gay has subsequently used other projective techniques, such as sentence completion tests and word association, and recently Turner (1978) successfully applied the same methods in studying the vernacular geography of the Sesotho people in Lesotho.

The Oluwatedo field trials, and the Ayo board experiments provide but one example of a technique which shifts the initiative in providing information to local people, or 'respondents' to give them their depersonalised form. This seems to be very important in oral cultures where questionnaire schedules can act as both steering wheel and brakes on the free flow of discussion. Paul Richards has subsequently used both questionnaires and $A y o$ techniques to interview farmers in Sierra Leone, and has tape recorded very positive assertions that they prefer the game format. An appropriate methodology, therefore, would use techniques which can structure an interaction so that the initiative rests with a local community, or an individual. A research strategy might thus involve a range of different methods such as projective techniques (Lindzey and Thorpe, 1968), and more limited forms of participant observation and questionnaire work, together with locally significant innovation in techniques. This type of multi-method approach, given carefully designed research programmes, could provide a variety of different learning formats and experiences for both research worker and farmer, and encourage mutual understanding and co-operation in agricultural research in developing countries.

\section{References}

Bannister, D., and F. Fransella, Inquiring Man, Penguin Books, 1971

Barker, D., 'A note on research methods in the study of Indigenous Environmental Knowledge', background paper for the IGU Workshop on Perception of Environmental Quality, University of Ibadan, Nigeria, 1978

Barker, D., J. Oguntoyinbo and P. Richards, The utility of the Nigerian peasant farmer's knowledge in the monitoring of agricultural resources, MARC Report No 4, Chelsea College, London, 1977.

Cole, M., J. Gay, J. A. Glick and D. W. Sharp, The cultural context of learning, Methuen, London, 1971

Crane, J. G. and M. V. Angrosino, Field projects in anthropology, General Learning Press, 1974

Lindzey, G. and J. S. Thorpe, 'Projective techniques', in D. L. Sills (ed), International Encyclopaedia of the Social Sciences, vol 14: 561-568, 1968

Murray, H. J. R., A History of board games other than chess, OUP, 1952

O'Keefe, E. and M. Howes, 'The uses of indigenous technical knowledge in development: an annotated bibliography', infra

Richards, P., 'Alternative strategies for the African Environment', in P. Richards (ed), African Environment, Special Report No 1, IAI, London, 1975

Turner, S., 'Sesotho farming: the condition and prospects of agriculture in the lowlands and foothills of Lesotho', unpub. Ph.D. thesis, University of London, 1978

Warwick, D. P., 'Survey research and participant observation: a benefit-cost approach', in D. P. Warwick and S. Osherton, Comparative research methods, Prentice-Hall, New Jersey: 189-204, 1973

Whyte, A., 'Guidelines for field studies in environmental perception', M.A.B. Technical Notes 5, 1977 